\title{
Consumers' Perception of Environmental and Health Benefits, and Consumption of Organic Vegetables in Bangkok
}

\author{
Sansern Srinieng and Gopal Bahadur Thapa*
}

\author{
*Correspondence: gopalthapa.ait@ \\ gmail.com \\ Asian Institute of Technology, Klong \\ Luang, Pathumthani, Thailand
}

\begin{abstract}
Factors influencing consumers' perception of environmental effects of organic agriculture, and health benefits and consumption of organic vegetables were determined using linear regression analyses of primary data collected through consumers' survey in Bangkok. Results revealed that household income, respondent's age and gender, access to information on organic vegetables, household members with health problems and location of residence in suburban area had significant positive influence on consumers' perceptions of environmental effects of organic agriculture and health benefits of organic vegetables. Perceptions of environmental effects of organic agriculture and health benefits of organic vegetables, organic vegetable prices, organic vegetable stores accessibility, and household income had significant positive influence on consumption of organic vegetables. Child in household had significant negative influence on consumption of organic vegetables, and causes are given. Relevant policy recommendations include creating effective consumers' awareness of health and environmental benefits of organic vegetables and wider promotion of organic vegetables consumption.
\end{abstract}

Keywords: Organic vegetables, Perception of environmental benefits, Perception of health benefits, Consumption, influencing factors, Bangkok

\section{Background}

As organic farm-produce are generated using inputs and methods that do not harm the producers' and consumers' health, and the environment as well, these are becoming increasingly popular not only in developed but also in developing countries (Altarawneh 2013; Kumar and Ali 2011; Gracia and de Magistris 2008). The Government of Thailand has been promoting the importance of organic agriculture since the enforcement of the First National Organic Agricultural Development Strategic Plan (Panyakul and Kongsom 2015). Under this Strategic Plan, policies and programs promoting organic agriculture have been implemented in the country (Kasem and Thapa 2012). Findings of empirical studies in selected areas in Thailand revealed certain significant achievements on the relative change in areas under organic farming over the years (Rattanasuteerakul and Thapa 2010). Despite the Government's effort, only 34,109.39 ha of land accounting for $0.29 \%$ of the total agricultural area in Thailand as of 2013 are devoted to organic farming. Consequently, there are only 9281 organic farms in the country accounting for $0.18 \%$ of

(c) The Author(s). 2018 Open Access This article is distributed under the terms of the Creative Commons Attribution 4.0 International License (http://creativecommons.org/licenses/by/4.0/), which permits unrestricted use, distribution, and reproduction in any medium, provided you give appropriate credit to the original author(s) and the source, provide a link to the Creative Commons license, and indicate if changes were made. 
Thailand's total agricultural farms. More particularly, the country's organic vegetable farming covers only 703.33 ha (Panyakul and Kongsom 2015).

In developing countries, organic farming is practiced at very low scale while most of the produce are meant for export (Lockie et al. 2006) since their domestic demand is still limited (Gamboni and Moscatelli 2015; Edwardson and Santacoloma 2013; Panmanee and Kongtanajaruanun 2012). Like any business ventures, the sustainable growth of organic farming is significantly influenced by the demand for organic produce. In Thailand, since the domestic demand for organic produce is limited, very small proportion of farmlands is currently being used for organic farming. Understanding the constrained demand for organic produce in the country is therefore crucial for the development and effective implementation of policies that aim to promote organic farming (Sriwaranun et al. 2015; Schleenbecker and Hamm 2013; Sangkumchaliang and Huang 2012).

The consumers' habits of purchasing and utilizing the goods and services explains how they make decisions to fulfill their needs (Parmaeswaran and Ramakrishnan 2013; Blackwell et al. 2006; Kotler 2000). Several factors affect the consumers' decision to purchase goods, which could be grouped into internal and external (Blackwell et al. 2006). Internal factors are the characteristics of individual consumers, including demographics, resources available at their disposal, motivation, knowledge, and attitude. External factors comprise culture, tradition, religion, as well as formal and informal relationships. However, the factors that influence consumers' behavior vary from one consumer to the other and from one area to another since the locations, and socio-economic and developmental features also vary from one area to another. Variations that exist among consumers in their capacity to access the resources, income, gender, age, and education, and in accessing information on the products and marketing stimuli such as quality, price, market place, and promotion, also significantly influence their decisions (Parmaeswaran and Ramakrishnan 2013; Blackwell et al. 2006; Kotler 2000).

Understanding the roles of psychographic, socio-economic, institutional, and policy factors in influencing the demand for organic foods had been attempted (Van Doorn and Verhoef 2015; Mohamad et al. 2014; Bravo et al. 2013; Nie and Zepeda 2011). Findings from some studies appear consistent but others are contradictory as the studies were carried out in different areas with heterogeneous biophysical, socio-economic, institutional, and political environments. Several studies noted that high income has a positive effect on the consumers' demand for organic food (e.g. Mohamad et al. 2014; Nie and Zepeda 2011; Roiner-Schobesberger et al. 2008) because consumers with relatively high income could afford to buy organic food, substantially priced higher than conventional food. In some instances (Wandel and Bugge 1997), high income did not influence the consumption of organic food because their inaccessibility affected the ability of some high-income people to purchase such food (Lockie et al. 2006). In some studies, consumption of organic food was also be influenced by consumers' satisfaction, in terms of the quality (Van Doorn and Verhoef 2015; Ozguven 2012; Hjelmar 2011; Aertsens et al. 2010) confirmed through the labels and/or certifications (Chen 2007), access to organic food stores (Bravo et al. 2013; Chen 2007), availability of variety of organic food (Bravo et al. 2013; Zagata 2012; Aertsens et al. 2010), and above all the price of organic food (Van Doorn and Verhoef 2015; Bravo et al. 2013; Sangkumchaliang and Huang 2012; Aertsens et al. 2010). 
Although the relatively high-income people have the tendency to buy organic food (Mohamad et al. 2014; Nie and Zepeda 2011) in spite of their higher price compared with the conventional food, this does not mean that these people would by default, buy organic food because these are easily available but because of their premium value in terms of health and environmental benefits. Since health is the most precious asset of any human being, most people would buy organic food as these would keep them healthy (Van Doorn and Verhoef 2015; Lockie et al. 2004). Another factor that contributes to the consumers' decision to patronize organic food is their perception of and concern about the environmental effects of environment-friendly farming systems (Bravo et al. 2013; Gracia and de Magistris 2008) which could also affect human health either directly or indirectly (Chen 2009). Nonetheless, only a handful of studies aimed at understanding the relationship between consumers' perception of the effects of organic food on their health have been published, and more so, these are less focused on environmental concerns (Ibitoye et al. 2014; Altarawneh 2013; Kumar and Ali 2011; Briz and Ward 2009). Therefore, policy-oriented research is necessary to find out the specific locations, and socio-economic and institutional factors that influence the consumers' behavior in purchasing organic food. The question therefore arises on the possible factors that could influence the consumers' perception of the environmental benefits of organic agriculture, the health benefits of organic vegetables, and consumption of organic vegetables, especially the perceptions of the residents of Bangkok, Thailand.

In Thailand, although few studies have been conducted to analyze the consumer's practice of eating organic food (Sangkumchaliang and Huang 2012) and the consumers' willingness to buy organic food (Sriwaranun et al. 2015; Panmanee and Kongtanajaruanun 2012), those studies failed to investigate whether or how consumers' perception of the environmental benefits of organic agriculture and health benefits of organic vegetables could influence their decision to consume organic vegetables. This study therefore makes an attempt to contribute to bridging this knowledge gap by determining the factors that influence the consumers' perception of the environmental and health benefits, and consumption of organic vegetables. The findings of this study could also serve as useful reference for the development of future policies on the promotion of organic food in general, and organic vegetables in particular, by the decision makers of the Government of Thailand.

\section{Methods}

\section{Study area}

Part of a comprehensive research carried out for the doctoral dissertation of the first author under the supervision of the second author, this study analyzed the various aspects of organic vegetable consumption, including consumers' willingness to buy organic vegetables, in Bangkok, Thailand, based on a consumers' survey conducted in Bangkok in 2013, Specifically, this study analyzed the consumers' perception of environmental benefits of organic agriculture and health benefits of organic vegetables; examined the factors that influence consumers' knowledge on and their willingness to purchase organic vegetables; and investigated the marketing margins of farmers, intermediaries and retail stores, including supermarkets, to determine whether the high retail price of organic vegetables is attributed to the high farm-gate prices of such vegetables or the 
high profit margins made by intermediaries and retailers. The sources of organic vegetables supplied to Bangkok, the largest concentrated market of organic vegetables in Thailand (Eischen et al. 2006), was identified. Information on the villages from where the organic vegetables were produced and supplied to Bangkok supermarkets and other vendors were obtained from the Department of Agricultural Extension, the public agency responsible for the promotion of organic farming. Finally, a farm household survey was carried out in Wang Nam Khio District of Nakhon Ratchasima Province, where groups of farmers were growing organic vegetables for sale to supermarkets and other stores through their respective cooperatives, as well as to specific areas and local organic vegetable retailers, Finally, two each of the supermarkets and "green stores" located in Din Daeng, Lat Phrao, Lak Si, and Vadhana Sub-districts of Bangkok, were selected for the consumers survey conducted during August to October 2015.

\section{Consumers sampling}

From the 217,442 households as of 2013 in the four sub-districts of Bangkok considered as the study area, a sample size of 384 was determined at $95 \%$ confidence level based on Cochran (1953). The sample consumers were randomly chosen at supermarkets and green stores that receive organic vegetables from farmers' cooperatives. Some residents in the study area aged more than 20 years old found to be cooking food at their homes were also considered in the study. The questionnaires were self-administered by the randomlypicked respondents but those who did not have time to fill out the questionnaires were immediately given envelopes bearing the author's postal return address and requested to return the completed questionnaires. Altogether, 214 respondents participated in the survey through this manner, while 170 respondents filled out the questionnaires on the spot. The respondents were asked to provide their personal data; household socio-economic characteristics; access to information and knowledge on organic vegetables; perception of environmental and health benefits of organic vegetables; satisfaction with the quality, labeling and/or certification; access to stores; variety of organic vegetables; price of organic vegetables; and consumption of organic vegetables.

\section{Data analysis}

The Statistical Package for Social Sciences (SPSS) was used to analyze the factors influencing the consumers' perception of the health benefits of organic vegetables and environmental effects of organic agriculture. Two continuous dependent variables, namely, the consumers' perception of environmental effects of organic agriculture $\left(\mathrm{Y}_{1}\right)$, and health benefits of organic vegetables $\left(\mathrm{Y}_{2}\right)$ were created using the five-point Likert scale as this scale can balance both sides of a neutral option, creating low bias measurement even if the actual scale varies. The highest score of 1.00 was given to the

"very strong" agreement with the "correct" statements about environmental effects of conventional and organic agriculture, and health effects of organic vegetables, which also implies that the concerned respondents perceived the environmental benefits of organic agriculture and health benefits of organic vegetables highly and correctly. The lowest score of 0.2 was assigned to "very little" agreement with the "correct" statements, implying that the concerned respondents minimally perceived the environmental benefits of organic agriculture and health benefits of organic vegetables. The calculated average 
scores of the perceptions of the environmental benefits of organic agriculture and health benefits of organic vegetables were grouped and interpreted as follows: very low $=0.01-$ 0.20 , low $=0.21-0.40$, moderate $=0.41-0.60$, high $=0.61-0.80$, and very high $=0.81-1.00$.

Similarly, the consumers' level of access to information on organic agriculture and satisfaction with the quality of organic vegetables were also measured using the Likert scale. The intensity of access to information was assigned the scores: $0.2=$ rarely, $0.4=$ occasionally, $0.6=$ moderately, $0.8=$ frequently and $1.0=$ often. Values of the levels of access to information were given the following ranges: rarely $=0.01-0.20$, occasionally $=0.21-0.40$, moderately $=0.41-0.60$, frequency $=0.61-0.80$, and often $=0.81-$ 1.00. For the level of satisfaction, a score of 0.2 was assigned for "strongly dissatisfied", 0.4 for "dissatisfied", 0.6 for "neutral", 0.8 for "satisfied", and 1.0 for "strongly satisfied". Values of the levels of satisfaction were assigned these ranges: strongly dissatisfied $=0.01-0.20$, dissatisfied $=0.21-0.40$, neutral $=0.41-0.60$, satisfied $=0.61-0.80$, and strongly dissatisfied $=0.81-1.00$.

As the dependent variable was seen to be continuous, stepwise multiple linear regression model was used to explore the factors that influence the consumers' perception of the environmental effects of organic agriculture $\left(\mathrm{Y}_{1}\right)$, and health benefits of organic vegetables $\left(\mathrm{Y}_{2}\right)$. The model is shown below, and the descriptive statistics of the independent variables included in the model are shown in Table 2.

$$
\mathrm{Y}=\mathrm{b}_{0}+\mathrm{b}_{1} \mathrm{X}_{1}+\mathrm{b}_{2} \mathrm{X}_{2}+\ldots .+\mathrm{b}_{12} \mathrm{X}_{12}
$$

Where $\mathrm{Y}$ is the degree of the consumers' perception of the environmental effects of organic agriculture $\left(\mathrm{Y}_{1}\right)$ and health benefits of organic vegetables $\left(\mathrm{Y}_{2}\right)$; $\mathrm{b}_{0}$ is a constant, and $b_{1}-b_{12}$ are the coefficients of the response variables $X_{1}-X_{12}$. This simulator was applied to the stepwise probability of $F \leq 0.05$ by adding the variables and to $F \geq 0.10$ by removing variables.

For analyzing the factors that influence the consumption of organic vegetables, a binary variable "consumers and non-consumers of organic vegetables" was created as the amounts of vegetables consumed widely varied among the respondents. Buyers of more than $20 \%$ of organic vegetables were considered to be organic vegetable "consumers" and assigned the score of "1", which corresponded to 152 respondents (39.6\%) in this study. Buyers of organic vegetables of up to $20 \%$ were considered to be "non-consumers" and were assigned the score of " 0 ", and corresponded to 232 respondents (60.4\%) as shown in Table 1.

A binary logistic regression model was used to find out the factors that influence the consumption of organic vegetables $\left(\mathrm{Y}_{3}\right)$. The model is shown below:

$$
\mathrm{Y}=\ln (\text { odds }(\text { even }))=\ln \left[\frac{\operatorname{prob}(\text { even })}{1-\text { prob }(\text { even })}\right]=\mathrm{b} 0+\mathrm{b}_{1} \mathrm{X}_{1}+\mathrm{b}_{2} \mathrm{X}_{2}+\ldots . .+\mathrm{b}_{21} \mathrm{X}_{21}
$$

Where $\mathrm{Y}$ is organic vegetable consumption $\left(\mathrm{Y}_{3}\right), \mathrm{b}_{0}$ is a constant, and $\mathrm{b}_{1}-\mathrm{b}_{20}$ are coefficients of the explanatory variables $\mathrm{X}_{1}-\mathrm{X}_{20}$. Using partial correlation analysis, this equation confirms the collinearity between the dependent and independent variables. Furthermore, the binary logistic regression model includes the independent variables that correlated significantly with the dependent variable and without multi-collinearity. The descriptive statistics of the variables included in the model are presented in Table 2. 
Table 1 Dependent variables included in the Stepwise Multiple Linear and Binary Logistic Regression Models $(n=384)$

\begin{tabular}{lll}
\hline Independent Variable & Average Index & Value \\
\hline 1. Perception of the environmental effects of organic agriculture $\left(Y_{1}\right)$ & 0.72 & High \\
2. Perception of health benefits of organic vegetables $\left(Y_{2}\right)$ & 0.78 & High \\
& $f$ & \\
3. Organic vegetable consumption $\left(Y_{3}\right)$ & & 60.4 \\
3.1 Non-consumers (0) & 232 & 33.1 \\
3.1.1 never bought OV & 127 & 27.3 \\
3.1.2 bought $\leq 20 \%$ OV & 105 & 39.6 \\
3.2 Consumers $(1)$ & 152 & 21.1 \\
3.2.1 bought 21-40\% OV & 81 & 10.4 \\
3.2.2 bought $41-60 \%$ OV & 40 & 3.9 \\
3.2.3 bought $61-80 \%$ OV & 15 & 4.2 \\
3.2.4 bought $>80 \%$ OV & 16 & \\
\hline
\end{tabular}

$f$ frequency of respondents

OV organic vegetables

\section{Results}

Factors influencing consumers' perception of the environmental effects of organic agriculture

In the analysis using the stepwise multiple linear regression final model with 5 independent variables, household income which explained $66 \%$ of the variance, was found to be the most influential variable followed by gender and age of respondents, access to information on organic agriculture, and presence of household member with a health problems (Table 3). These five variables combined explained $73 \%$ of the total variance in the consumers' level of perception of the environmental effects of organic agriculture illustrated by the final simulator. The $F$ value shows the statistical significance of the model at confidence level of 0.000 . The predictive factors in this simulator were justified, which significantly explained the dependent variable. The Durbin-Watson statistics of 1.61 meant that there was neither a first-order serial correlation nor an auto-correlation.

The results show that there is a tendency towards an increase in consumers' correct perception of the environmental effects of organic agriculture with increasing household income, female respondents, access to information on organic vegetables, and respondents' age, and household member with health problems (Table 4). Of the five significant variables, the most significant was access to information on organic agriculture, followed by household income, respondents' gender and age, and household member with health problems.

\section{Factors influencing consumers' perception of health benefits of organic vegetables}

In the analysis of the final model of the stepwise multiple linear regression containing 6 independent variables, household income which explained $72 \%$ of the variance was found to be the most influential variable followed by respondents' age and gender, access to information on organic vegetables, household member with health problems, and household location (Table 5). These six variables combined explained about $80 \%$ of the 
Table 2 Descriptions of independent variables included in the Stepwise Multiple Linear and Binary Logistic Regression Models $(n=384)$

\begin{tabular}{|c|c|c|c|c|}
\hline $\begin{array}{l}\text { Descriptions of } \\
\text { variables }\end{array}$ & Specifications & $\begin{array}{l}\text { Types of } \\
\text { variables }\end{array}$ & $\begin{array}{l}\text { Level/Scale } \\
\text { of variables }\end{array}$ & $\begin{array}{l}\text { Mean } \\
\text { value }\end{array}$ \\
\hline \multicolumn{5}{|l|}{ Socio-economic variables } \\
\hline Gender $\left(X_{1}\right)$ & Male (0), Female (1) & Dummy & 2 & - \\
\hline $\begin{array}{l}\text { Location of residence } \\
\left(X_{2}\right)\end{array}$ & Suburb (0), Core area (1) & Dummy & 2 & - \\
\hline $\operatorname{Age}\left(X_{3}\right)$ & Respondents' age (years) & Continuous & - & 42.4 \\
\hline Education $\left(\mathrm{X}_{4}\right)$ & $\begin{array}{l}\text { Primary School (1), Secondary School (2), Bachelor's } \\
\text { Degree (3), Master's Degree and higher (4) }\end{array}$ & Categories & 4 & - \\
\hline Occupation $\left(X_{5}\right)$ & $\begin{array}{l}\text { Not permanently employed (0), Permanently } \\
\text { employed (1) }\end{array}$ & Dummy & 2 & - \\
\hline Household income $\left(X_{6}\right)$ & $\begin{array}{l}\text { Less than } 25,000 \text { Baht }(1), 25,000-50,000 \text { Baht (2), } \\
50,001-75,000 \text { Baht (3), } 75,001-100,000 \text { Baht (4), } \\
\text { Higher than 100,000 Baht (5) }\end{array}$ & Categories & 5 & - \\
\hline Household size $\left(X_{7}\right)$ & Number of household members & Continuous & - & 3.9 \\
\hline Children HHM $\left(\mathrm{X}_{8}\right)$ & No $(0)$, Yes (1) & Dummy & 2 & - \\
\hline Elderly HHM $\left(X_{9}\right)$ & No (0), Yes (1) & Dummy & 2 & - \\
\hline $\begin{array}{l}\text { HHM with health } \\
\text { problem }\left(X_{10}\right)\end{array}$ & No (0), Yes (1) & Dummy & 2 & - \\
\hline Vegetarian HHM $\left(X_{11}\right)$ & No $(0)$, Yes (1) & Dummy & 2 & - \\
\hline \multicolumn{5}{|c|}{ Access to information on organic vegetables (OV) } \\
\hline $\begin{array}{l}\text { Access to information } \\
\text { on } \mathrm{OV}\left(\mathrm{X}_{12}\right)\end{array}$ & Index of intensity & Continuous & 5 & 0.55 \\
\hline $\begin{array}{l}\text { Knowledge on } \\
\text { characteristics of OV }\left(X_{13}\right)\end{array}$ & Incorrect (0), Correct (1) & Dummy & 2 & - \\
\hline \multicolumn{5}{|c|}{ Perception of the environmental and health benefits of OV } \\
\hline $\begin{array}{l}\text { Environmental benefits } \\
\left(X_{14}\right)\end{array}$ & Index of perception & Continuous & 5 & 0.72 \\
\hline Health benefits $\left(X_{15}\right)$ & Index of perception & Continuous & 5 & 0.78 \\
\hline \multicolumn{5}{|l|}{ Satisfaction with OV } \\
\hline Quality $\left(X_{16}\right)$ & Index of satisfaction & Continuous & 5 & 0.77 \\
\hline $\begin{array}{l}\text { Labelling/certification } \\
\left(X_{17}\right)\end{array}$ & Index of satisfaction & Continuous & 5 & 0.75 \\
\hline $\begin{array}{l}\text { Access to market/stores } \\
\left(X_{18}\right)\end{array}$ & Index of satisfaction & Continuous & 5 & 0.55 \\
\hline Variety $\left(X_{19}\right)$ & Index of satisfaction & Continuous & 5 & 0.56 \\
\hline Price $\left(X_{20}\right)$ & Index of satisfaction & Continuous & 5 & 0.60 \\
\hline
\end{tabular}

$H H M$ household member

$\mathrm{OV}$ organic vegetables

total variation in the consumers' level of perception of the health benefits of organic vegetables. The $F$ value in the final model was statistically significant at confidence level of 0.00. The result suggests that the factors comprising the model were justified and significantly influenced the consumers' level of the correct perception of the health benefits of organic vegetables. The Durbin-Watson statistics of 1.64 meant that there was neither a first-order serial correlation nor an auto-correlation.

The five independent variables-household income, respondents' age, respondents' gender, respondents' access to information on organic vegetables, and household member with health problems-were positively correlated with the dependent variable, whereas 
Table 3 Summary of factors influencing the consumers' perception of the environmental effects of organic agriculture based on Stepwise Multiple Linear Regression Model

\begin{tabular}{lllllc}
\hline Model & $R$ & $R$ square & Adjusted $R$ square & Std. error of the estimate & Durbin-Watson \\
\hline 1 & $0.810^{1}$ & 0.657 & 0.656 & 0.11952 & \\
2 & $0.833^{2}$ & 0.694 & 0.692 & 0.11307 & 1.61 \\
3 & $0.846^{3}$ & 0.716 & 0.714 & 0.10903 & \\
4 & $0.852^{4}$ & 0.727 & 0.724 & 0.10707 & \\
5 & $0.855^{5}$ & 0.730 & 0.727 & 0.10649 & \\
\hline
\end{tabular}

1 Predictors: (Constant), Household income

2 Predictors: (Constant), Gender of respondent

3 Predictors: (Constant), Access to information on OV

4 Predictors: (Constant), Age of respondent

5 Predictors: (Constant), HHM with health problem

household location was negatively correlated, implying that respondents in the central part of the Bangkok were either unaware or less aware of the health benefits of organic vegetables (Table 6). There was a tendency towards increasing the consumers' correct perception of the health benefits of organic vegetables with increasing household income, respondents' age, female respondents, access to information on organic vegetables, and presence of a household member(s) with health problems. Moreover, living in suburban areas had positively influenced the correct perception of the health benefits of organic vegetables.

\section{Factors influencing the consumption of organic vegetables}

The result of the correlation analysis predicted 18 independent variables significantly correlated with the dependent variable and, therefore, qualified for inclusion in the model. The two insignificantly correlated variables were location of household $\left(\mathrm{X}_{2}\right)$ and occupation of respondents $\left(\mathrm{X}_{5}\right)$.

Using the maximum likelihood estimates of the parameters in the binary logistic regression model were used to determine the factors influencing the consumption of organic vegetables, the result indicated that the $\mathrm{R}$ square increased with the addition of the independent variables, while the regression model test statistics indicated that the model is highly significant. Overall, the model correctly predicted $60.4 \%$ of the variation in organic vegetable consumption. Thus, the factors comprising this model are correct.

The effects of the independent variables on the consumption of organic vegetables are shown in Table 7. The results indicated a tendency towards the consumption of organic vegetables among households with a relatively high income, perception of environmental effects of organic agriculture, perception of health benefits of organic vegetables, satisfaction with access to organic vegetable stores, and satisfaction with the price of organic vegetables. On the contrary, there was a tendency towards less consumption of organic vegetables among households with relatively elder members and children.

\section{Reasons for consuming organic and conventional vegetables}

As mentioned in Section Data Analysis, an overwhelming majority of respondents were found consuming both organic and conventional vegetables, and relatively a small percentage of the respondents were consuming conventional vegetables only. To validate 
Table 4 Coefficients of Variables of factors influencing consumers' perception of the environmental effects of organic agriculture using Stepwise Multiple Linear Regression Model

\begin{tabular}{lllllll}
\hline Variable & \multicolumn{2}{l}{ Unstandardized coefficient } & & $\begin{array}{l}\text { Standardized coefficient } \\
\text { neta }\end{array}$ & t value & Sig. \\
\cline { 2 - 3 } & $\mathrm{B}$ & Std. Error & & & \\
\hline (Constant) & 0.190 & 0.027 & & 7.125 & .000 \\
Household income & 0.083 & 0.007 & 0.521 & 12.747 & $.000^{* *}$ \\
Gender of respondent & 0.054 & 0.014 & 0.134 & 3.919 & $.000^{* *}$ \\
Access to information on OV & 0.201 & 0.037 & 0.155 & 5.452 & $.000^{* *}$ \\
Age of respondent & 0.002 & 0.001 & 0.132 & 3.239 & $.001^{* *}$ \\
HHM with health problem & 0.040 & 0.015 & 0.106 & 2.710 & $.007^{* *}$ \\
\hline
\end{tabular}

NB: ** Significant at $p<0.01$

the results of the logistic regression analysis, consumers of both types of vegetables and consumers of conventional vegetables only were asked to provide the reasons for their consumption behavior, where the former was first asked about their reasons for consuming organic vegetables. As a result, an overwhelming majority of both types of vegetable consumers reasoned that they consume such vegetables because these are produced using organic inputs only (Table 8 ). Such perception could have led to nearly $90 \%$ of both types of vegetable consumers mentioning that they consume organic vegetables as these are healthier than conventional vegetables. This reason for consuming organic vegetables is consistent with the first reason. Again, consistent with the first two main reasons, nearly $60 \%$ of both types of vegetable consumers said that they consume organic vegetables because conventional vegetables are not good for one's health.

When the respondents were asked about the main reasons for consuming both types of vegetables, nearly three-fourths of them said that they cannot afford to buy organic vegetables only as their prices are much higher than that of conventional vegetables (Table 8). Nearly the same percentage of respondents said that only a few varieties of organic vegetables are available in organic stores and that the vegetables that they consume are oftentimes not available in organic stores.

For the consumers of only conventional vegetables, most of them attributed their consumption behavior to the high price of organic vegetables (Table 8), which is consistent with one of the reasons given for not consuming organic vegetables only by consumers of both types of vegetables. Interestingly, nearly $68 \%$ of conventional vegetable

Table 5 Summary of factors influencing consumers' perception of health benefits of organic vegetables using Stepwise Multiple Linear Regression

\begin{tabular}{lllllc}
\hline Model & $R$ & $R$ square & Adjusted $R$ square & Std. error of the estimate & Durbin-Watson \\
\hline 1 & $0.852^{1}$ & 0.725 & 0.725 & 0.10254 & \\
2 & $0.878^{2}$ & 0.770 & 0.769 & 0.09388 & 1.64 \\
3 & $0.892^{3}$ & 0.796 & 0.794 & 0.08862 & \\
4 & $0.897^{4}$ & 0.805 & 0.803 & 0.08674 & \\
5 & $0.901^{5}$ & 0.811 & 0.809 & 0.08546 & \\
6 & $0.904^{6}$ & 0.817 & 0.814 & 0.08434 & \\
\hline
\end{tabular}

1 Predictors: (Constant), Household income

2 Predictors: (Constant), Age of respondent

3 Predictors: (Constant), Gender of respondent

4 Predictors: (Constant), Access to information on OV

5 Predictors: (Constant), HHM with health problem

6 Predictors: (Constant), Location of residence 
Table 6 Coefficients of Variables of factors influencing consumers' perception of health benefits of organic vegetables using Stepwise Multiple Linear Regression Model

\begin{tabular}{|c|c|c|c|c|c|}
\hline \multirow[t]{2}{*}{ Variable } & \multicolumn{2}{|c|}{ Unstandardized coefficient } & \multirow{2}{*}{$\begin{array}{l}\text { Standardized coefficient } \\
\text { Beta }\end{array}$} & \multirow[t]{2}{*}{ t value } & \multirow[t]{2}{*}{ Sig. } \\
\hline & $B$ & Std. error & & & \\
\hline (Constant) & 0.230 & 0.025 & & 9.378 & $0.000^{* *}$ \\
\hline Household income & 0.085 & 0.006 & 0.519 & 14.761 & $0.000^{* *}$ \\
\hline Age of respondent & 0.003 & 0.001 & 0.196 & 5.616 & $0.000^{* *}$ \\
\hline Gender of respondent & 0.058 & 0.012 & 0.141 & 4.776 & $0.000^{* *}$ \\
\hline Access to information on OV & 0.117 & 0.033 & 0.088 & 3.586 & $0.000^{* *}$ \\
\hline HHM with health problem & 0.048 & 0.013 & 0.122 & 3.664 & $0.000^{* *}$ \\
\hline Location of residence & -0.030 & 0.009 & -0.076 & -3.335 & $0.001^{* *}$ \\
\hline
\end{tabular}

NB: ** Significant at $p<0.01$

consumers did not see any difference between the conventional and organic vegetables. Moreover, nearly the same percentage of conventional vegetable consumers considered that such vegetables are safe for one's health when produced without applying inorganic inputs such as pesticides.

\section{Access to sources of information on organic vegetables}

In this study, the respondents indicate moderate access to information on organic vegetables, as shown in Table 9. The sources of their information which they frequently accessed were the internet (0.73) and television (0.65), although they also moderately obtained information from their friends and relatives.

\section{Discussion}

Factors influencing consumers' perception of the environmental and health benefits of organic vegetables

Although one's health is the prime concern of human beings, the environment should also be a matter of equal importance as conventional agriculture which uses chemical inputs could also affect in one way or other, the health of the environment. Nonetheless, when the awareness of people of the effects of conventional agriculture on the environment is enhanced, they would be convinced to express their increasing concern on the need to protect the environment (Hemmerling et al. 2015; Falguera et al. 2012; Hjelmar 2011; Haghiri et al. 2009). Many people now consider the environment as gift of nature with an inherent right to remain healthy, but since the environment itself cannot express such right, human beings have the duty to respect this right as it would also benefit them in return. Consumers with such altruistic vision are aware of agricultural produce that are beneficial or harmful to the environment, and are also able to see the connection between the environment and human health. The findings of this study clearly indicate that consumers in Bangkok, in general, very strongly consider organic agriculture as environment-friendly. Similarly, they also strongly believe that organic vegetables are beneficial to their health. Such perception is directly attributed to their frequent access to information on organic agriculture and organic vegetables through popular sources such as the internet and television (Table 9). As most people in Bangkok have their own personal computers and smart phones, they could easily access the information on any topics of their interest including those on organic agriculture. 
Table 7 Analysis of maximum likelihood estimates of organic vegetable consumption

\begin{tabular}{lllll}
\hline Variable & B & Wald & $P$-value & Exp(B) \\
\hline Gender & 0.496 & 0.111 & 0.739 & 1.642 \\
Age & -0.133 & 6.311 & $0.012^{*}$ & 0.876 \\
Education & -0.034 & 0.003 & 0.957 & 0.966 \\
Household income & 3.961 & 8.668 & $0.003^{* *}$ & 52.504 \\
Household size & 0.412 & 1.377 & 0.241 & 1.509 \\
Children HHM & -2.358 & 5.020 & $0.025^{*}$ & 0.095 \\
Elderly HHM & 0.519 & 0.186 & 0.666 & 1.680 \\
HHM with health problem & -2.591 & 3.823 & 0.051 & 0.075 \\
Vegetarian HHM & -0.308 & 0.145 & 0.703 & 0.735 \\
Access to information on OV & -1.698 & 0.293 & 0.588 & 0.183 \\
Knowledge on characteristic of OV & -2.075 & 2.418 & 0.120 & 0.126 \\
Perception of environmental effects of organic agriculture & 9.788 & 5.722 & $0.017^{*}$ & $17,818.067$ \\
Perception of the health benefits of OV & 17.428 & 9.343 & $0.002^{* *}$ & $37,068,838.027$ \\
Satisfaction with OV quality & -5.265 & 1.345 & 0.246 & 0.005 \\
Satisfaction with organic labelling/certification & -0.414 & 0.020 & 0.887 & 0.661 \\
Satisfaction with access to OV stores & 12.965 & 8.653 & $0.003^{* *}$ & $427,296.947$ \\
Satisfaction with variety of OV & -2.259 & 0.305 & 0.581 & 0.104 \\
Satisfaction with price of OV & 17.144 & 18.119 & $0.000^{* *}$ & $27,893,445.213$ \\
\hline
\end{tabular}

NB: * Significant at $P<0.05,{ }^{* *}$ Significant at $P<0.01$

The increasing perception of consumers of the environmental effects of organic agriculture and health benefits of organic vegetables correctly, with their increasing household income, is consistent with the findings of Altarawneh (2013), Briz and Ward (2009), and Haghiri et al. (2009). This could be attributed to the consumers' education and their habit of seeking information which had been enhanced with increased income that also raised their correct perception of the health benefits of organic vegetables and the environmental effects of organic agriculture. Furthermore, findings from this study

Table 8 Reasons for consuming vegetables (Multiple-Response)

\begin{tabular}{lll}
\hline Reasons & $f$ & $\%$ \\
\hline $\begin{array}{l}\text { 1. Main Reasons for Consuming OV }(n=257) \\
\text { Healthier than conventional vegetables }\end{array}$ & 225 & 87.5 \\
Free from inorganic inputs & 194 & 75.5 \\
Conventional vegetables are not good for health & 148 & 57.6 \\
2. Main Reasons for Consuming Both OV and CV $(n=241)$ & & 72.6 \\
High price of organic vegetables & 175 & 71.4 \\
Not many varieties of OV & 172 & 71.4 \\
Vegetables that we consume often are not available in the stores & 172 & 93.7 \\
3. Main Reason for Consuming CV only ( $n=127)$ & & 67.7 \\
$\quad$ High price of organic vegetables & 119 & 66.9 \\
$\quad$ Do not see a difference between conventional and organic vegetables & 86 & \\
Inorganic pesticide free vegetables are safe & 85 & \\
\hline$f$ frequency of respondents & & \\
OV organic vegetables & &
\end{tabular}


Table 9 Sources of information on organic vegetables

\begin{tabular}{llc}
\hline Source of Information & Index of intensity & Value \\
\hline Internet & 0.73 & Frequently \\
TV & 0.65 & Frequently \\
Friends and relatives & 0.57 & Moderately \\
Printed materials & 0.51 & Moderately \\
Agriculture exhibitions & 0.49 & Moderately \\
Radio & 0.43 & Moderately \\
Average & 0.55 & Moderately \\
\hline
\end{tabular}

which indicate that female respondents are more aware of the environmental and health benefits associated with organic agriculture and organic vegetables, respectively than their male counterparts is valid because in Thailand, women normally have the greater responsibility of buying and cooking food for their families. They also have greater responsibility in taking care of their children and the elderly as well as the sick household members. Obviously, they are always seeking information related to health and the effects of different kinds of foods including organic vegetables. However, this does not conform to results of other studies which showed that gender insignificantly influence the consumers' perception of the environmental and health benefits of organic produce (Altarawneh 2013; Kumar and Ali 2011).

The significant positive effect of respondents' age on their correct perception of the environmental and health benefits of organic vegetables is sensible. With gradual increase in age, consumers become more increasingly concerned about their health, and are keen in collecting information on the effects of different kinds of foods on their health. This is however, inconsistent with the findings of the study by Altarawneh (2013), which indicated that age had no relationship with consumers' perception on this aspect. The presence in a household of a sick person was also found in this study to have an influence on the consumers' correct perception of both the environmental and health benefits of organic vegetables, which is natural because most people in Thailand are concerned about the health of their sick household members and thus, would always seek information on the health and environmental effects of organic produce and become aware of the positive and negative effects of organic and conventional vegetables, respectively. Interestingly, the result of the analysis revealed that consumers who are living in suburban areas are more aware of the health effects of organic vegetables than the consumers living in the core part of the city, which could be explained by the fact that normally high- and medium-income consumers are inclined to live in the suburbs.

\section{Factors influencing the consumption of organic vegetables}

The results indicating that significant consumption of organic vegetables is positively influenced by consumers' perception of environmental benefits of organic agriculture and health benefits of organic vegetables (Table 6) support the proposition of this study, and is consistent with the findings of earlier studies conducted in Thailand (Sangkumchaliang and Huang 2012; Roiner-Schobesberger et al. 2008). The increasing concern of people about the environment also has direct bearing on their consumption of organic food (Hsu and Chen 2014; Bravo et al. 2013; Ozguven 2012; Aertsens et al. 
2010). Consumers who are well aware of the environmental effects of organic agriculture and the health benefits of organic vegetables and vis-à-vis those of conventional vegetables, recognize that their household members, including the children, the sick and elderly, would benefit more by consuming organic vegetables and that such produce would also contribute to the conservation of the environment, which in turn would also be beneficial to themselves. In so doing, they satisfy their altruistic vision about keeping the precious gift of nature safe and clean. Therefore, the consumers who are concerned about environmental conservation and healthy life have a tendency towards purchasing organic foods (Hemmerling et al. 2015; Goetzke et al. 2014; Hsu and Chen 2014; Mohamad et al. 2014; Bravo et al. 2013; Ozguven 2012; Sangkumchaliang and Huang 2012; Hjelmar 2011; Haghiri et al. 2009).

Normally prices of organic vegetables are considerably higher than that of conventional vegetables because of the health and environmental benefits of the former (Hemmerling et al. 2015; Bravo et al. 2013). In Bangkok, the prices of some organic vegetables could be more than double the prices of conventional vegetables. For example, the average price of conventional Chinese kale and Chinese cabbage was $116 \mathrm{Baht} / \mathrm{kg}$ during the time of the survey for this study, whereas the prices of the organic variant of these vegetables at the supermarkets were 250 Baht and 150 Baht $/ \mathrm{kg}$, respectively (Srinieng 2017). Consistent with this, past studies on organic produce showed that organic vegetables in Bangkok could command prices that are $88-170 \%$ higher than that of conventional vegetables (Sriwaranun et al. 2015; Roiner-Schobesberger et al. 2008). Obviously, even the medium-income consumers not to mention the low-income consumers, would not be able to purchase organic vegetables regularly despite their perception that organic vegetables are beneficial for their health and that organic agriculture is beneficial for the environment. As also implied through this study, the capacity of the respondents to buy organic vegetables is significantly and positively associated with the household income of consumers. Such findings are reinforced by the overwhelming concern of majority of both conventional and organic vegetable consumers who mentioned that they could not consume organic vegetables due to their very high prices (Table 8). For such reason, most of the so-called organic vegetable consumers in Bangkok are consuming both types of vegetables. Our findings are in conformity with several other studies (Hemmerling et al. 2015; Mohamad et al. 2014; Nie and Zepeda 2011; Onyango et al. 2006; Magnusson et al. 2001).

Another reason given by respondents for not consuming organic vegetables only is the unavailability of the vegetables of their choice. There are very limited varieties of organic vegetables available in the market, and some of them are consumed as salad only. Cauliflowers, cabbage, and different varieties of leafy vegetables and gourds, which are consumed daily by the Thais with their staple food rice, are mostly inorganic and are much cheaper than organic vegetables. Moreover, only few stores are selling organic produce in Bangkok and, more so, these stores are not easily accessible to most people. Consumers, therefore, have no other alternative except to consume both organic and conventional vegetables.

As shown in Table 6, the consumers' perception of the health benefits of organic vegetables rises as their age increases. However, the respondents indicated that their consumption of organic vegetables is reduced as they get older. This contradicts with the findings of other studies, which revealed a tendency towards increasing consumption 
of organic food with increasing age of consumers (Mohamad et al. 2014; Bravo et al. 2013; Nie and Zepeda 2011). In the case of Bangkok, such findings of this study could be attributed to two factors. Firstly, it is possible that the annual household incomes of older people are lower than that of the young generation of consumers for being more economically versatile than the older people. Another reason could be due to the fact that even with lower income, older people's household expenses could be higher than that of the younger generation. This is because in Thai society, parents normally support their children's education up to the university level while their health-related expenses gradually increase as they get older. Since the prices of organic vegetables are much higher than that of conventional vegetables, a decrease in income or increase in household expenses would be detrimental to the people's desire to buy and consume organic vegetables.

A study carried out in Denmark showed that households with children buy more organic food (Hjelmar 2011) because most people are more concerned about the effect of food, firstly on their children's health and secondly, on older people's health. Normally, the children and older people are more vulnerable to all sorts of health problems due to their weak immune systems. Logically, households with children are supposed to consume organic vegetables. Nevertheless, findings of this study do not support this supposition as the results of the regression analysis showed a negative association between organic vegetables consumption and households with children. This might be partly explained by the fact that normally, households with children incur higher expenses than households without children, as substantial portion of family's income is usually expended on raising and educating the children, thereby making it difficult for most families to buy and consume organic vegetables.

Consumption of organic vegetables is positively influenced by the consumers' satisfaction with the accessibility of green stores and the prices of green produce (Table 7). Consumers in Bangkok are usually confronted with the inaccessibility of organic vegetable stores as only few stores are selling such vegetables. Obviously, consumers who are living relatively close to organic stores are buying organic vegetables, but vice-versa in the case of non-consumers. Better distribution of organic stores therefore improves consumers' access to organic produce, eventually increasing the consumption of such products (Bravo et al. 2013; Zanoli and Naspetti 2002). Likewise, consumers' satisfaction with the price has positive influence on the consumption of organic vegetables, implying that people who can afford organic vegetables, despite their high prices, are the ones satisfied with the price. Affordability, as revealed by the findings of the logistic regression analysis in this study, is directly related to the consumers' household incomes.

Additionally, this study revealed that two-thirds of consumers of conventional vegetables do not see any difference between organic and conventional vegetables (Table 8), which could partly explain the reasons for consuming both organic and conventional vegetables. Such findings however, somewhat contradict with the results of the analysis of consumers' perception of health benefit of organic vegetables, which revealed very high positive perception of health benefits of organic vegetables. Nonetheless, the respondents seemed to be still confused about the advantages and disadvantages of conventional and organic vegetables. This intimates that the efforts made by both government and non-government organizations to create public awareness of the advantages of organic and conventional agricultural products are not very effective. 


\section{Conclusions and recommendations}

Consumers' access to relevant information plays a significant role in creating the perception of the health and environmental benefits of organic vegetables, implying that information is a driving force for any cognitive change that ultimately enhances the consumers' interest in eating such vegetables. Realizing the significance of access to information, government and non-government agencies are enhancing their efforts to disseminate information on organic agriculture, in general, and organic vegetables, in particular, through the internet, television and newspapers. People in Bangkok can also have easy access to information on organic agriculture as these are oftentimes, posted on the internet by individuals and agencies at large. However, some of the consumers in the capital city of Bangkok still could not distinguish the difference between organic and conventional vegetables. This underlines the need to launch an aggressive media campaign in an effective way by concerned government agencies in cooperation with organic vegetable producers and sellers for people to change their perceptions of the effects of consuming organic and conventional vegetables. The primary target of such campaign should be the relatively young as well as male and female consumers living in the core area of the city. The role of the mass media such as television and the internet would be very crucial in disseminating the information on the health and environmental benefits of organic vegetables. Concerned agencies could also consider raising the public's awareness of the health and environmental benefits of consuming organic vegetables and the harmful effects of conventional produce through educational institutions, by encouraging these institutions to integrate such topics into the relevant courses. As today's children are tomorrow's potential buyers of organic produce, making them aware of the benefits of consuming such produce through school education would help in promoting the consumption and production of organic produce. Moreover, being convinced about the environmental and health benefits of organic produce, the school children could serve as catalysts in motivating their parents to buy and consume such produce.

The consumers' perception and knowledge on organic produce are certainly important factors that influence their decision to consume such produce. However, the findings of this study suggest that it would be quite difficult to promote the consumption of organic vegetables and other organic produce at a wider scale unless their prices are brought down to the levels that are affordable for common consumers. This is reinforced by the findings that even households with children and elderly members could not consume organic vegetables, in spite of knowing that consumption of such vegetables would be good for the health. Therefore, prior to designing any policy intervention to bring down the prices of organic vegetables, it is essential to find out whether the high price is attributed to the cost of production or marketing.

Based on the findings of this study, easy access to organic stores and availability of organic vegetables commonly consumed by people with their meals are also essential conditions to promote the consumption of organic vegetables at a wider scale. Learning lessons from the findings of this study, formulation of any policy intervention should address these current shortcomings, such difficult access to organic stores and unavailability of organic vegetables commonly eaten with people's meals. In this regard, it is crucial that the distribution system is improved in such way that more and more producers, intermediaries and retailers would be attracted to the distribution and marketing systems of organic vegetables. 
Some studies carried out elsewhere have found that the taste (Hjelmar 2011; Aertsens et al. 2010) and quality, including product freshness (Roininen et al. 2006), and packaging (Ibitoye et al. 2014), also influence the consumption of organic vegetables. Additionally, the altruistic motivations such as animal welfare could also motivate organic vegetables consumption (Bravo et al. 2013; Zander and Hamm 2010). This study however, had not considered these factors.

Authors' contribution

Both authors read and approved the final manuscript.

Competing interests

The authors declare that they have no competing interests.

\section{Publisher's Note}

Springer Nature remains neutral with regard to jurisdictional claims in published maps and institutional affiliations.

Received: 11 June 2017 Accepted: 21 February 2018

Published online: 14 March 2018

\section{References}

Aertsens J, Mondelaers K, Verbeke W, Buysse J, Van Huybenbroeck G (2010) The influence of subjective and objective knowledge on attitude, motivations and consumption of organic food. Brit Food J 113(11):1353-1378

Altarawneh M (2013) Consumer awareness towards organic food: a pilot study in Jordan. JAFT 3(12):14-18

Blackwell R, D'Souza C, Taghian M, Miniard P, Engel JF (2006) Consumer behaviour : an Asia Pacific approach. Thomson South Melbourne

Bravo C, Cordts A, Schulze B, Spiller A (2013) Assessing determinants of organic food consumption using data from the German National Nutrition Survey II. Food Qual Prefer 28(1):60-70

Briz T, Ward RW (2009) Consumer awareness of organic products in Spain: an application of multinominal logit models. Food Policy 34(3):295-304

Chen M (2007) Consumer attitudes and purchase intentions in relation to organic food in Taiwan: moderating effects of food-related personality traits. Food Qual Prefer 18(7):1008-1021

Chen M (2009) Attitude toward organic foods among Taiwanese as related to health consciousness, environmental attitudes, and the mediating effects of a healthy lifestyle. Brit Food J 111(2):165-178

Cochran WG (1953) Sampling Techniques. Wiley, New York

Edwardson W, Santacoloma P (2013) Organic supply chains for small farmer income generation in developing countries: case studies in India, Thailand, Brazil, Hungary and Africa. FAO, Rome

Eischen E, Prasertsri P, Sirikeratikul S (2006) Thailand's organic outlook 2006. USDA foreign Agricultural Service, Bangkok

Falguera V, Aliguer N, Falguera M (2012) An integrated approach to current trends in food consumption : moving toward functional and organic products. Food Control 26(2):274-281

Gamboni M, Moscatelli S (2015) Organic agriculture in Italy: challenges and perspectives. Org Agric 5(3):165-177

Goetzke B, Nitzko S, Spiller A (2014) Consumption of organic and functional food. A matter of well-being and health? Appetite 77(1):94-103

Gracia A, de Magistris T (2008) The demand for organic foods in the south of Italy: a discrete choice model. Food Policy 33(5):386-396

Haghiri M, Hobbs JE, McNamara ML (2009) Assessing consumer preferences for organically grown fresh fruit and vegetables in Eastern New Brunswick. Int Food Agribus Manage Rev 12(4):81-100

Hemmerling S, Hamm U, Spiller A (2015) Consumption behaviour regarding organic food from a marketing perspective-a literature review. Org Agric 5(4):277-313

Hjelmar U (2011) Consumers' purchase of organic food products. A matter of convenience and reflexive practices. Appetite 56(2):336-344

Hsu CL, Chen MC (2014) Explaining consumer attitudes and purchase intensions toward organic food: contributions from regulatory fit and consumer characteristics. Food Qual Prefer 35:6-13

Ibitoye OO, Nawi NM, Kamarulzaman NH, Man N (2014) Consumers' awareness towards organic rice in Malaysia. Int Food Res J 25(5):1711-1718

Kasem S, Thapa GB (2012) Sustainable development policies and achievements in the context of the agriculture sector in Thailand. Sustain Dev 20(2):98-114

Kotler P (2000) Marketing management, millennium edition. Prentice-Hall, USA

Kumar S, Ali J. (2011). Analyzing the factors affecting consumer awareness on organic foods in India. Paper present at the meeting of the $21^{\text {st }}$ annual IFAMA world forum and symposium on road to 2050: sustainability as a business opportunity, Frankfurt, 20-23 June 2011

Lockie S, Halpin D, Gordon R, Pearson D (2006) Understanding the market for organic food. In: Taji A, Reganold J (eds) Organic Agriculture: A Global Perspective. Cornell University, New York

Lockie S, Lyons K, Lawrence G, Grice J (2004) Choosing organics: a path analysis of factors underlying the selection of organic food among Australian consumers. Appetite 43(2):135-146

Magnusson MK, Arvola A, Hursti UK, Aberg L, Sjoden PO (2001) Attitudes toward organic foods among Swedish consumers. Brit Food J 103(3):209-227 
Mohamad SS, Rusdi SD, Hashim NH (2014) Organic food consumption among urban consumers: preliminary results. Procedia Soc Behav Sci 130:509-514

Nie C, Zepeda L (2011) Lifestyle segmentation of US food shoppers to examine organic and local food consumption. Appetite 57(1):28-37

Onyango B, Bellows AC, Diamond A, Hallman W (2006) What we don't understand about public interest in organics. Appetite 47(3):384-401

Ozguven N (2012) Organic foods motivations factors for consumers. Procedia Soc Behav Sci 62:661-665

Panmanee C, Kongtanajaruanun R (2012) Willingness to pay and ability to pay for fresh organic vegetables of the consumers in Chiang Mai Province. Maejo University, Chiang Mai

Panyakul V, Kongsom C (2015) Project study of production and marketing situation of organic agriculture. Ministry of Commerce, Bangkok

Parmaeswaran R, Ramakrishnan S (2013) A study on consumer purchase behaviour towards organic products. IJSR 4(8): 1906-1908

Rattanasuteerakul K, Thapa GB (2010) Towards organic vegetable farming in Mahasarakham province, Thailand. J Sustain Agr 34(1):57-79

Roiner-Schobesberger B, Darnhofer I, Somsook S, Vogl CR (2008) Consumer perceptions of organic foods in Bangkok, Thailand. Food Policy 33(2):112-121

Roininen K, Arvola A, Lähteenmäki L (2006) Exploring consumers' perception of local food with two different qualitative techniques: laddering and word association. Food Qual Prefer 17:20-30

Sangkumchaliang P, Huang W (2012) Consumers' perceptions and attitudes of organic food products in northern Thailand. Int Food Agribus Manage Rev 15(1):87-102

Schleenbecker R, Hamm U (2013) Consumers' perception of organic product characteristics. A review. Appetite 71:420-429

Srinieng S (2017) Consumption of organic vegetables in Bangkok, Thailand

Sriwaranun Y, Gan C, Lee M, Cohen DA (2015) Consumers' willingness to pay for organic products in Thailand. Int J Soc Econ 42(5):480-510

Van Doorn J, Verhoef PC (2015) Drivers of and barriers to organic purchase behaviour. J Retailing 91(3):436-450

Wandel M, Bugge A (1997) Environmental concern in consumer evaluation of food quality. Food Qual Prefer 8(1):19-26

Zagata L (2012) Consumers' beliefs and behavioral intensions towards organic food. Evidence from the Czech Republic Appetite 59(1):81-89

Zander K, Hamm U (2010) Consumer preferences for additional ethical attributes of organic food. Food Qual Prefer 21: 495-503

Zanoli R, Naspetti S (2002) Consumer motivations in the purchase of organic food. A means-end approach. Brit Food J 104(8):643-653

\section{Submit your manuscript to a SpringerOpen ${ }^{\circ}$ journal and benefit from:}

- Convenient online submission

- Rigorous peer review

- Open access: articles freely available online

- High visibility within the field

- Retaining the copyright to your article 